the gouge or gouge forceps to remove as much more as might have been necessary. Doubtless, this method of proceeding has been adopted by other surgeons, but I have been unable to find any case so operated on recorded. A point of interest about the growth is its character. The original growth when removed at Guy's Hospital is reported to be myeloid sarcoma. Again, when the patient presented herself at St. Thomas's Hospital the growth was described as a myeloid sarcoma. The appearance of the tumour now, however, has appeared to have undergone a change, for there are only a few myeloid cells to be seen, while the bulk of the tumour seems to be made up of a firm fibrous stroma interspersed with a large number of small round cells. Another interesting point is that when Mr. Lucas removed the growth in June, 1885 , he did not remove any of the hard palate. Now, however, the whole of the hard palate is absorbed, having been destroyed by the tumour. There is no doubt the growth commenced in the periosteum of the hard palate, for Mr. Lucas is reported to have scraped the base, after removal of the growth with scissors, and from its point of origin the tumour grew upwards and right and left, absorbing the bony structures as it extended, at the same time pushing its way outwards into the cavities of the antra, and upwards between the othmoidal spongy bone.

Upper.Wimpole-street, $W$.

\section{A FEW FACTS CONCERNING THE RECENT PREVALENCE OF WINTER DIARRHCEA. ${ }^{1}$}

BY SHIRLEY I. MURPHY,

IECTURER ON HYGIEYE AND PUBLIC HEALTH, ST. MARY'S HOSPITAL.

I HAVE thought that our Society might well have before it a few facts which $I$ have been able to glean concerning the recent prevalence of diarrhœe during the winter months. The subject was first referred to in a paragraph in THE LANCET of Feb. 5th, which also contained the following week a letter from Mr. C. H. Taylor of the West London Hospital, stating that diarrhcea was prevalent in Fulham, Chiswick, and Hammersmith; and the British Medical Journal of the same date published a communication from Dr. Norman Kerr telling the same story for the neighbourhood of Regent's-park. Later, other correspondents bore witness to the existence of epidemic diarrhoa in St. James's, Bayswater, Marylebone, Clapham, Lewisham, Penge, Kingston-on-Thames, Kent, and even as far from London as Lancashire and Aberdeenshire. The reports of the symptoms from which the patients suffered fairly well agreed. In all cases there was diarrhœa, in the majority abdominal pain, vomiting, cramps in the limbs, great depression, and a symptom of particular interest -- high temperature. In a few the fact was noted that the patients also suffered from hæmorrhage from the bowels. In many instances the sufferers were attacked in the night, and often in groups, suggesting community of cause. We may assume therefore, in the first instance, that the epidemic, wherever it manifested itself, was of the same nature, and that some of the symptoms to which it gave rise were those not usually met with in ordinary diarrh oea, and that, regarding it as diarxhoea, the disease occurred at an unusual period of the year. We are led, moreover, to conclude that, notwithstanding the area which its operations covered, it is in the highest degree probable that the cause in each locality was the same. And 1 may go further, and say that this cause was not related to any climatic condition; for, if we examine the dates of outbreaks in public institutions situated near to each other, and therefore subject to the same climatic conditions, we do not find that these dates exactly correspond; and, further, some institutions also in the neighbourhood of those which were invaded escaped altogether. The cause must, nevertheless, be one capable of operating over large extents of country.

My own opportunities for learning some particulars of this illness were practically limited to its behaviour in a special hospital in Central London, which I first visited for that purpose on Jan. 27th. I was informed by the senior housesurgeon, who had taken great interest in the matter, that half the inmates of the institution about two months before

1 Read at a meeting of the Society of Medical Officers of Health, May 20th, 1887. had been attacked suddenly with diarrbœea, the patients alone suffering and the staff altogether escaping. On Jan. 25th the incident repeated itself, nearly fifty persons on this occasion being attacked. The distribution of the disease in the hospital is of importance; for again, on the second occasion, the patients were, with trifling exceptions, the only sufferers. The patients are resident in wards situated on three floors; those on each floor taking their meals mostly together. On the tirst floor are beds for thirty women, on the second floor beds for forty men, and on the third floor twenty-six beds, twenty-one of which are occupied by men and the rest by children. Of the patients resident in the hospital at the time of my visit, I found that on the first floor there were attacked on Jan.24th (Ionday) in the morning one, in the evening three; on the 2.5th (Tuesday), in the morning two, in the evening six; on the 26th (Wednesday), in the morning one. On the second floor there were attacked on Jan. 24th (Monday), in the evening one; on the 25th (Tuesday), in the morning eighteen. On the third floor there were attacked, on Jan. 24th (Monday), in the evening five; on the 25 th (Tuesday), in the morning six. Or, considering those on th different floors together-on Monday, Jan. 24th, ten were attacked; on Tuesday the 25th, thirty-two; and on Wednesday the 26th, one; the majority of the attacks occurring while the patients were in bed at some period of the night.

The most striking circumstance in the outbreak is the almost complete immunity enjoyed by the staff. Of twentytwo persons engaged either in attendance upon the sick or in domestic duties, but two suffered from diarrhoea, and these were nurses, both of whom were attacked in the early morn. ing of Tuesday, Jan. 25th.

To enable the exact incidence of the disease upon the patients to be determined, and for the purposes of further inquiry, I ascertained the condition of health of those who had been discharged from the hospital for some time previously, and in this manner elicited information that no patient who left the hospital before Jan. 24 th was attacked On Thursday, Jan. 20th, three patients were discharged, and on Friday, the 21st, three; on Saturday, the 22nd, six: none of whom suffered. On Sunday, the $23 \mathrm{rd}$, no patients were discharged; on Monday, the 24th, six patients were discharged, three of whom were attacked early the following morning at their own homes. Whatever cause, therefore, gave rise to diarrhca probably came into operation after the patients left on Jan. 22nd--i.e., after midday dinner on that day. Of patients newly admitted into the hospital, three admitted on Jan. 20th were each attacked; of two admitted on the 21st, one was attacked; and of three admitted on the $22 \mathrm{nd}$, two were attacked. None were admitted on Sunday, Jan. $23 \mathrm{rd}$. Five were admitted on Jan. 24th, all of whom escaped. T'wo were admitted on Jan. 25th, both of whom escaped. The cause of the outbreak therefore probably ceased to be operative before the patients were admitted on Monday, Jan. 24 th - i.e., the cause was operative only some time between midday on Saturday, Jan. 22nd, and midday on Monday, Jan. 24th.

It becomes important, therefore, to ascertain the effect of this cause upon the patients who were in the hospital at this particular time, changes by admissions and discharges having taken place before my visit. There were sixty patients in the hospital between Jan. 22nd (Saturday), midday, and Jan. 24th (Monday), midday, of whom forty-three were attacked with diarrhæa, either within the hospital or immediately after their return home, giving a percentage of 76.6 . Of the staff I have already said there were twentytwo, of whom two were attacked, or 9 per cent. This difference is so great that I was compelled to regard the condition causing the diarrhoea as one with which the prtients must be specially related, and this view was strengthened by the fact that the two affected members of the staff were nurses who may likely enough have come into accidental relation with this condition.

At this period I was not aware that the disease was prevalent in other parts of England, and I was led to examine the incidence of attack upon patients taking milk, water, and other articles of food. Of those who drank unboiled water at their meals there were thirty-three, of whom twenty-five were attacked, or 75.7 per cent., being practically identical with the general average. Of those who drank no water except that which they had in their tea, and which had therefore been boiled, there were twenty-six, of whom twenty-one were attacked, or 807 per cent. Drinking water 
or abstaining from water did not therefore affect the probabilities of attack. Again, ferty-four patients drank uncooked milk instead of beer, and of these thirty-four were attacked, or $7-2$ per cent., a proportion equal to the general average. Of tifteen patients who took no milk except in tea, thirteen Were attacked, or $86^{\circ} 6$ per cent. Drinking or abstaining from milk cannot therefore be said to have affected the probabilities of attack. Nerertheless, the large proportion of gttacks among patients, and the immunity enjoyed by the staff, strongly indicated some article of food as responsible for the occurrence. The senior house-surgeon was good enough to prepare for me a complete list of all the articles of food consumed in the hospital. I may at once eliminate from further suspicion the following:--Milk, because the supply was common to staff and patients, because of the evidence already adduced, and also because the same farms supplied milk to another large hospital, which remained free from disease. Water, because it was consumed by staff and patients, and because of the evidence already adduced. The possibility that the local contamination of a cistern was responsible for the outbreak may be set aside by consideration of the fact that separate cisterns supplied the different floors. Tea and salt may be eliminated, because the supply was common to staff and patients. Meat and potatoes, because the supply was common to staff and patients. Beef-tea, because it was only consumed by a few patients. Beer, because those who did not drink beer were also attacked. Bread and sugar, because the same articles consumed by the patients were also supplied to the servants, none of whom were attacked. Rice, because no fresh supply had been received for a long time previously, and the children had been eating rice daily without injury. I may also refer to the fact that other institutions and other parts of the country were invaded, having different milk, water, and meat supplies.

There is but one article of food I am unable to exculpate, and to the possibility of this being the cause of a widespread outbreals I would desire to direct the attention of the Society. I refer to butter, which in the method of its distribution in the hospital in the first instance raises a presumption that it may have been concerned in producing this curious disease. Three qualities of butter were supplied to the institution - (a) that provided for the medical officers and matron, $(b)$ that provided for the nurses and servants, and (c) that provided for the patients. The patients' butter is received on every weekday at 10 A.M., and is used for tea and supper the same day and for breakfast the following day, on Saturdays the supply being increased to last until breakfast on the following Monday morning. If we assume that the butter received for the patients on Saturday, Jan. 22nd, possessed purgative properties, there is ample explanation of the illness of all the patients who suffered from diarrhoea. That all were not attacked at the same time, and that some escaped, may be due to some unequal distribution of the active principle throughout the butter, or perbaps to some difference in the quantity consumed. There remain the attacks of two nurses, who, it may be mentioned, suffered less severely than the patients from this malady. I have no other explanation to offer on this point than that they must have eaten some portion of the bread-and-butter not required for the patients. Those who are intimate with hospital life will know that this is no unusual event. Thus far as to this particular hospital. The difficulty which stands in the way of the acceptance of this theory is the fact that other institutions-many persons not living in institutions, and other parts of the country have also shared in the prevalence of diarrhœa.

English butter is made upon the farm on which the milk is produced, and the few pounds which each farm is able to contribute could not be sufficiently widely distributed to give rise to an occurrence such as that we have under consideration. But the butter which I have been led to suspect was that provided for the patients, and low-priced butters come largely from abroad. In other countries butter is not alkays manufactured on the farms on which the milk is produced, but large numbers of farms send their milk to central depôts, where, I am told, the milk of hundreds of farms is mixed together, made into butter, and colouring matter added, which always gives to it a uniform colour and flavour. This is sent over in enormous quantities to the English middle-man, who distributes it to local rendors, from whom it reaches the consumers. In this manner any capacity which the milk from any farm might possess to cause diarrhœea would, if due to an organism, have the possibility of being multiplied by admixture of this milk with other milk, and thus its effects might be felt in many places. Or perhaps the method of treatment of the butter in some central depôt might be concerned in conferring upon it this power, or possibly by the development of some chemical poison it might have acquired this special property. The symptoms of the sufferers, indeed, remind us of the observations of Dr. Victor C. Vaughan of Michigan concerning the effects of a ptomaine he found in cream. It is, under any circumstance, conceivable that butter which possesses this property might be distributed through different channels over a large area of country, and thus induce diarrhcea in one district or institution at one time and in another at the same or at a different time.

I have not had the opportunity of extending my inquiries sufficiently to enable me to thoroughly sift the evidence that could be obtained outside the institution with which 1 was concerned. I therefore prefer to leave the subject where it is, but I may mention incidentally that one large hospital which also suffered heavily received its butter from the same source as that which came under my own observation, and that another suffering very partially required the patients to supply their own butter, thus giving opportunity for it to be procured from many sources, of which perhaps one only was identical with that under suspicion. This difference in the method of supply may perhaps account for the smallness of the number of persons affected in some institutions. I do not wish now to do more than urge--1st, that the nature of the epidemic of which we have recently had experience points to an article of food as the cause; 2 nd, that the facts learnt at one institution, where they were carefully observed, point especially to butter; and, 3rd, that any objection to this theory, which is based on the method of distribution of butter made on English farms, falls to the ground when the distribution of foreign and of artificial butters is considered. In conclusion, I would desire very cordially to thank Mr. E. Treacher Collins, whose active assistance has enabled me to ascertain the facts upon which this story is based, and to whose accurate observation I am very greatly indebted.

\section{DEATH FROM IMPACTION OF GALL-STONES.}

BF A. GLOVER WILLTAMS, M.D., M.R.C.S., SURGEON TO THE BRIXTON DISPENSARY.

ON October 13th, 1886, I was called to see Mrs. B-. She was a woman of dark complexion, with rather an anxious expression, and was markedly jaundiced, the conjunctivæ being of a deep yellow. She was fairly well nourished. I was told that three months ago she was seized with pain below the right ribs, which gradually became intense; it was more or less paroxysmal in character, accompanied b.y violent sickness, and followed in a day or two by yellowness of the skin. A medical man was called in, who said she was suffering from the passage of gall-stones. She suffered from the pain and sickness as short intervals until three weeks or a month ago, when the pain left her; but the sickness increased, notwithstanding, until she could keep nothing down; the jaundice also deepened. Her friends told me that she had been somewhat addicted to drink. She was under my care from October 26th to November 12th, 1884, and was then suffering from symptoms of gall-stone colic-viz., acute pain in the right hypochondriac region, with sallowness of the conjunctivæ, which did not amount to jaundice; the urine contained some bile, and the fæces were pale-i.e., clay-coloured; the motions were searched for gall-stones, but none were found. In July, 1885, she again came under my notice with the same symptoms. There was no actual jaundice on this occasion, and no gall-stones were found in the fæces. In March, 1886, she had a similar attack, but on this occasion she was jaundiced; the pain then left her suddenly, but her recovery was gradual. She says that her father had some operation performed on his lip, but she does not know what for.

The patient's present condition (Oct. 13th, 1886) is as follows: She has lost all pain, but suffers from constant sickness. She retains nothing; even the medicine is returned. The vomit is of a dark-greenish colour, almost wholly fluid, and about the consistence of thin gruel. The bowels are 